\title{
МИКРОСТРУКТУРА И МЕХАНИЧЕСКИЕ СВОЙСТВА СРЕДНЕМАРГАНЦЕВОЙ СТАЛИ ПОСЛЕ РАЗЛИЧНЫХ ДЕФОРМАЦИОННЫХ И ТЕРМИЧЕСКИХ ОБРАБОТОК
}

\author{
(C) 2020 г. В. И. Торганчук ${ }^{1, ~ *, ~ А . ~ Н . ~ Б е л я к о в ~}{ }^{1}$ \\ ${ }^{1}$ Федеральное государственное автономное образовательное учреждение высшего образования \\ “Белгородский государственный национальный исследовательский университет”, Белгород, Россия \\ *E-mail: torganchuk@bsu.edu.ru \\ Поступила в редакцию 18.02 .2020 г. \\ После доработки 16.03.2020 г. \\ Принята к публикации 27.03.2020 г.
}

\begin{abstract}
Исследовано влияние режимов деформационных и термических обработок на структурно-фазовое состояние и механические свойства перспективной среднемарганцевой экономнолегированной стали $\mathrm{Fe}-10 \mathrm{Mn}-0.2 \mathrm{C}$. Определен температурный интервал двухфазной области с высоким содержанием объемной доли аустенитной фазы.
\end{abstract}

DOI: $10.31857 / \mathrm{S} 0367676520070303$

\section{ВВЕДЕНИЕ}

Развитие автомобилестроения в значительной степени определяется свойствами доступных конструкционных материалов. Разработка новых сталей и изменение технологических процессов их производства направлены на решение нескольких задач. Основными задачами являются повышение безопасности пассажиров и снижение вредных выбросов, в том числе за счет снижения массы транспортного средства. На сегодняшний день отечественная автомобильная промышленность пытается участвовать в решении поставленных задач за счет использования высокопрочных сталей. Так, например, доля высокопрочной стали в "АВТОВАЗе" постоянно увеличивается с $9 \%$ у LADA Priora до $36 \%$ в LADA Vesta. С этой целью ведется закупка современного оборудования из Японии, Кореи и европейских стран. Однако имеющиеся отечественные высокопрочные стали не обладают достаточной технологичностью, способной в полной мере использовать потенциал имеющегося оборудования, что обусловливает актуальность разработки новых экономнолегированных сталей [1, 2].

За последние двадцать лет на правительственном уровне были предприняты меры по снижению негативного воздействия транспортных средств на окружающую природу более чем в два раза [2]. Этого удалось достичь, в том числе, за счет применения новых легких металлов и их сплавов. В то же время, такое развитие событий влечет за собой множество нерешенных вопросов, связан- ных с соединением новых легких материалов с широко известными сталями. Традиционная сварка плавлением сопровождается выделением интерметаллидов при кристаллизации, которые приводят к охрупчиванию сварного соединения [3]. Coвременная промышленность еще не готова к производству новых конкурентоспособных материалов из цветных сплавов, обладающих всеми заявленными свойствами, которые имели бы невысокую стоимость. Кроме того, использование цветных металлов и их сплавов накладывает определенные ограничения, одним из которых является пригодность к ремонту вне специализированных полупромышленных мастерских с дорогостоящим громоздким оборудованием.

С целью укрепить позиции конструкционных сталей на фоне возрастающих требований к свойствам материалов была создана ассоциация "World Auto Steel" ("Мировые автомобильные стали"), в состав которой вошли крупнейшие производители стали со всего мира. Наша страна представлена компанией ПАО “Северсталь” [4]. Основные усилия по реализации поставленных задач направлены на развитие высокопрочных сталей (HSS) и усовершенствованных высокопрочных сталей (AHSS). На сегодняшний день требование улучшения баланса прочности и пластичности привело к появлению сталей с повышенным содержанием марганца. За счет этого образовался новый класс сталей с пластичностью, наведенной двойникованием, как правило, это стали с содержанием марганца в пределах 17-24 мас. \% [5]. Особый интерес автомобильной промышленности сосредоточен на 
усовершенствовании полученных сталей с целью сокращения содержания марганца и других легирующих элементов. Одним из новых типов высокопрочных сталей являются сплавы с пластичностью, наведенной фазовым превращением ("TRIP-стали") [6]. Высокий баланс прочности и пластичности в таких сталях достигается благодаря мартенситному превращению остаточного аустенита в процессе пластической деформации. Мартенситное превращение приводит к увеличению скорости деформационного упрочнения при более высоких степенях деформации, тем самым сдерживая локализацию пластического течения и способствуя равномерной деформации, что повышает пластичность. Целесообразность использования сталей, по сравнению, например, с алюминием, заключается в более экологичном способе ее производства (в несколько раз), а также способах ее переработки, что может косвенно влиять на снижение вредных выбросов в атмосферу [2].

Особое внимание необходимо уделить системе легирования данного класса сталей. Состав стали должен обеспечивать необходимый фазовый состав, а именно стабилизировать аустенитную фазу при комнатной температуре. В связи с этим к данным сталям предъявляются особые требования к деформационным и термическим обработкам, позволяющим сформировать необходимый структурно-фазовый состав. Кроме механических свойств, данные стали должны обладать хорошей технологичностью, в частности, хорошей свариваемостью [7]. С этой целью ограничивается концентрация легирующих элементов. Основной вклад в упрочнение дает углерод, но при концентрациях, превышающих 0.2 мас. \% существует ограничение по свариваемости. В предыдущих работах показано, что среднемарганцевые стали с высоким содержанием углерода 0.6 мас. \% можно сваривать с использованием сварки трением с перемешиванием, при этом зона сварного соединения обладает повышенной прочностью относительно материала основы, что должно благоприятно сказаться на надежности свариваемых деталей [8]. К сожалению, сварка трением с перемешиванием пока не получила широкого распространения в автомобилестроении. Для расширения номенклатуры сталей, которые можно использовать при проектировании конструкции транспортного средства, в рамках данной работы исследована экономнолегированная среднемарганцевая сталь с содержанием углерода 0.2 мас. $\%$.

\section{МАТЕРИАЛ \\ И МЕТОДЫ ИССЛЕДОВАНИЯ}

В качестве материала исследования была выбрана сталь со средним содержанием марганца $\mathrm{Fe}-10 \mathrm{Mn}-0.2 \mathrm{C}(\mathrm{Fe}-0.2 \mathrm{C}-10.7 \mathrm{Mn}-0.02 \mathrm{Al}-0.05 \mathrm{Si}$ фактический химический состав в массовых про- центах). Сталь была получена методом электрошлакового переплава в водоохлаждаемый кристаллизатор. Исследования проводили на стали в горячекатаном и теплокатаном состояниях. Предварительно слитки гомогенизировали при температуре 1423 К в течение 4 ч. Горячую продольную прокатку проводили при температуре 1423 К с суммарным обжатием $60 \%$, с последующим охлаждением в воду. Теплую прокатку с суммарным обжатием 60\%, с последующим охлаждением в воду проводили при температуре 823 К, при которой содержание аустенита и феррита в стали составляет $1: 1$ по данным программного комплекса ThermoCalc. Отжиги проводили в муфельных печах, контроль температуры осуществляли в центральной области печи вблизи образца.

Структурные исследования проводились с использованием сканирующего электронного микроскопа Nova NanoSem (SEM), оборудованного анализатором дифракционной картины обратнорассеяных электронов (EBSD), включающим программный комплекс TSL OIM Analysis 7, и просвечивающего электронного микроскопа JEOL JEM-2100. Рентгенофазовый анализ образцов проводили с использованием рентгеновского дифрактометра (Rigaku, Ultima IV) с $\mathrm{Cu}$ К $\alpha$-излучением. Рабочее напряжение для рентгеновского дифрактометра составляло 40 кB, ток 30 мА, а диапазон сканирования и размер шага составляли $35^{\circ}-120^{\circ}$ и $0.02^{\circ}$ соответственно. Образцы для электронной микроскопии и рентгеноструктурного анализа были подготовлены с использованием электролитической полировки при комнатной температуре при напряжении 18В с применением электролита A2 STRUERS.

Серия испытаний на растяжение была выполнена при скорости деформации $10^{-3} \mathrm{c}^{-1}$ на универсальной испытательной машине INSTRON 5882. Микротвердость измеряли методом Виккерса с использованием микротвердомера Wolpert 402MVD c нагрузкой 0.5 Н и временем выдержки 10 c.

\section{РЕЗУЛЬТАТЫ И ИХ ОБСУЖДЕНИЕ}

Исследования структурно-фазового состояния проводились на образцах после деформационной обработки и последующего отжига в широком температурном интервале. Влияние температуры отжига на фазовый состав стали представлено на рис. 1. С увеличением температуры объемная доля аустенитной фазы увеличивается, достигая максимума при 923 К, а затем снижается при дальнейшем увеличении температуры отжига. Проведенное термодинамическое моделирование фазового состава (рис. 1), показывает похожую тенденцию роста объемной доли аустенитой фазы с увеличением температуры до $923 \mathrm{~K}$, при которой доля аустенита достигает $100 \%$ и не меняется при дальнейшем увеличении температуры. 


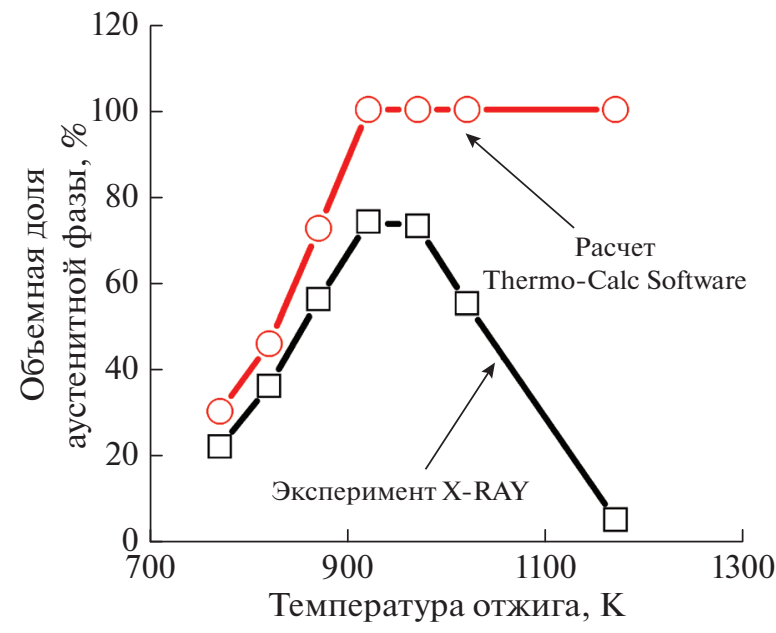

Рис. 1. Влияние температуры отжига на содержание объемной доли аустенитной фазы.

Проведенные микроструктурные исследования показывают формирование двухфазного состояния после изотермической прокатки при $823 \mathrm{~K}$ со средним размером аустенитного зерна около 300 нм. Последующая термическая обработка при температуре $773 \mathrm{~K}$ не приводит к заметному изменению аустенитного зерна (рис. $2 a$ ). Увеличение температуры отжига до 873 К приводит к увеличению объемной доли аустенитной фазы и увеличению среднего размера зерна (рис. 2б). При
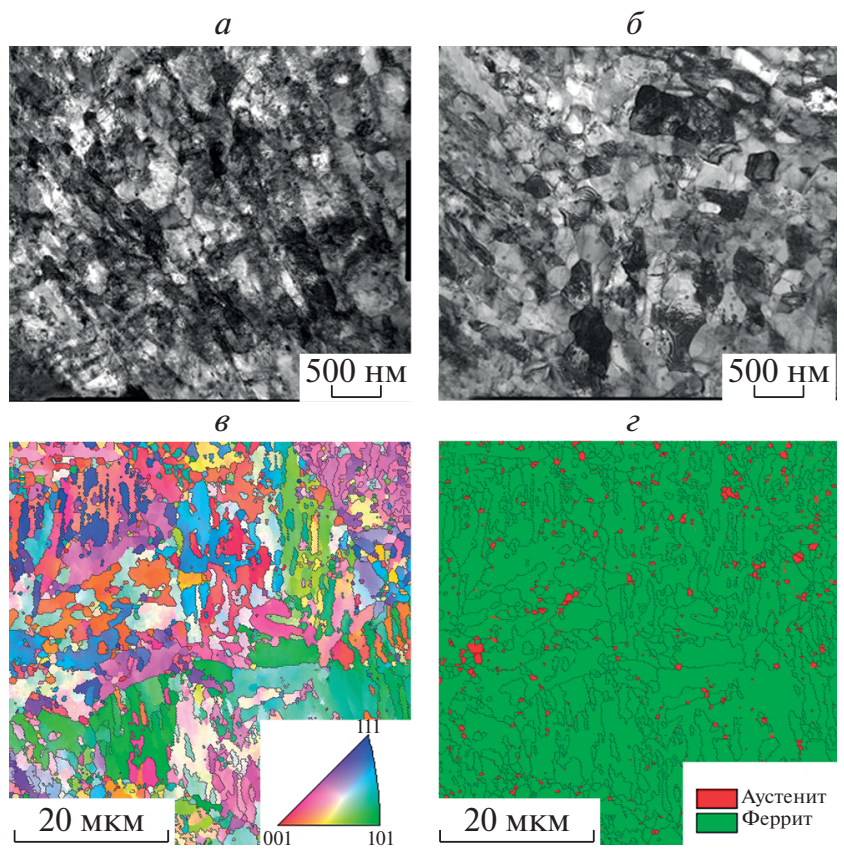

Рис. 2. Микроструктура стали $\mathrm{Fe}-10 \mathrm{Mn}-0.2 \mathrm{C}$ после отжига при различных температурах: $773(a), 873$ (б), 1173 К (в) и его фазовый состав (2). температуре $1173 \mathrm{~K}$ происходит рост размера исходного аустенитного зерна до 20 мкм (рис. 26). После отжига при 1173 К и охлаждения до комнатной температуры объемная доля аустенита составляет $4 \%$ (рис. 22). Полученные данные хорошо согласуются с рентгенофазовым анализом.

Тенденция изменения микротвердости в зависимости от температуры отжига стали после прокатки при температуре $823 \mathrm{~K}$ показана на рис. 3 . Наблюдается монотонное увеличение микротвердости с увеличением температуры отжига. В диапазоне температур 1023-1173 K ее показатели соответствуют $450 \mathrm{HV}$.

При проведении механических испытаний на одноосное растяжение образцов, вырезанных вдоль направления прокатки, было обнаружено, что в исходном состоянии (после горячей деформации) исследуемая сталь обладает невысокой пластичностью, относительное равномерное удлинение составило около 5\%. При этом предел текучести и предел прочности составляют 465 и 1340 МПа соответственно. Последующая прокатка при 823 К приводит к увеличению предела текучести и предела прочности до 700 и 1630 МПа соответственно. Данный метод деформационной обработки позволил увеличить пластичность (относительное удлинение до разрушения) более чем в 4 раза.

Термодинамическое моделирование фазового состава стали $\mathrm{Fe}-10 \mathrm{Mn}-0.2 \mathrm{C}$ с использованием программного комплекса ThermoCalc позволило определить, что для данной стали характерно формирование двухфазной области в интервале температур 573-923 К. Увеличение температуры в данном интервале приводит к росту объемной доли аустенитной фазы от $10 \%$ до максимума (100\%) при 923 К. Как можно заметить, проведенные исследования структурно-фазового состояния с ис-

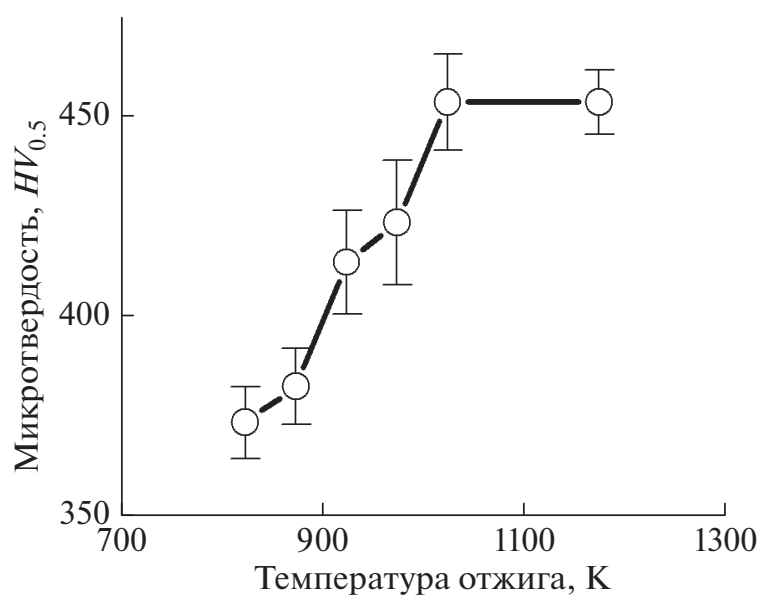

Рис. 3. Влияние температуры отжига на изменение микротвердости стали после прокатки при температуре $823 \mathrm{~K}$. 
пользованием рентгенофазового анализа выявили похожую тенденцию изменения объемной доли аустенитной фазы в интервале температур 773-923 К, за исключением того, что ее значения отличаются от значений моделирования фазового состава. Такое различие может быть связано с тем, что определение фазового состава программным комплексом ThermoCalc соответствует непосредственно температуре моделирования, в то время как рентгенофазовый анализ был проведен на образцах после отжига при заданной температуре и последующего охлаждения до комнатной температуры.

Было проведено дополнительное исследование влияния времени выдержки на фазовый состав исследуемой стали. Увеличение времени выдержки до двух часов при заданной температуре не выявили существенного изменения фазового состава, наблюдалось лишь ухудшение качества поверхности исследуемой стали в результате образования толстого слоя окалины.

Интересно отметить, что при температуре $923 \mathrm{~K}$ наблюдается резкое снижение объемной доли аустенитной фазы. Такое поведение можно объяснить на основе данных термодинамического расчета. При данной температуре отжига должна наблюдаться полностью аустенитная структура. Увеличение ее объемной доли сопровождается перераспределением легирующих элементов, (в результате снижается их концентрация в аустенитной матрице), которые определяют стабильность ГЦК-фазы при комнатной температуре. В результате при охлаждении происходит фазовое превращение, о чем свидетельствуют данные рентгенофазового анализа. Микроструктурные исследования, полученные с использованием электронной просвечивающей и растровой микроскопии, подтверждают предложенный механизм структурообразования после охлаждения с повышенных температур (рис. 2).

При температуре 873 К формируется двухфазная структура с уменьшенной объемной долей остаточного аустенита относительно рассчитанного фазового состава (рис. 1). При этом можно видеть, что при температуре отжига 1173 К продолжается рост аустенитного зерна до 20 мкм, но при охлаждении происходит фазовое превращение, в результате которого резко снижается объемная доля аустенита (рис. 22). Интересно отметить, что такое снижение слабо влияет на изменение микротвердости исследуемой стали в диапазоне температур отжига 1073-1173 К.

Данный класс сталей является конструкционным, и наряду с технологическими операциями сварки необходима и формуемость, а технологической пластичности, например, такой, как после горячей деформации при 1423 К, будет недостаточно для придания необходимой геометрии из-

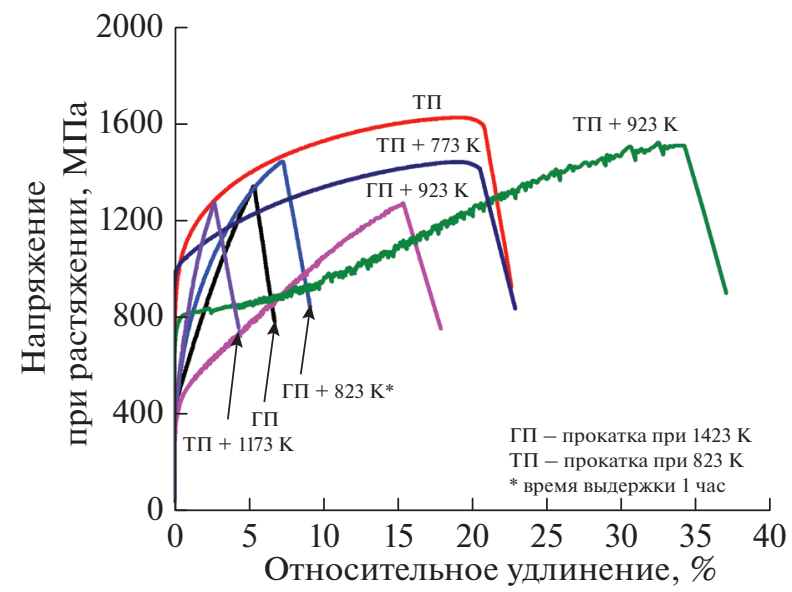

Рис. 4. Инженерные диаграммы деформации при испытании на одноосное растяжение.

делию при пониженных температурах. В свою очередь, недостаточная пластичность может привести к снижению общего уровня безопасности конечного изделия. С целью устранения выявленного недостатка разработанной стали была проведена теплая прокатка при температуре $823 \mathrm{~K}$, которая по результатам термодинамического моделирования определена как оптимальная по соотношению фаз феррита и аустенита для получения необходимого комплекса механических свойств. Предложенная деформационная обработка позволила почти двукратно увеличить предел текучести и поднять предел прочности до уровня 1630 МПа. Кроме того, данный метод обработки позволил увеличить пластичность (относительное удлинение до разрушения) более чем в 4 раза, что существенно позволит увеличить область применения разработанной перспективной стали. Использование повышенного содержания марганца (10\% вес.) позволяет получить сплав, обладающий комплексом высокой прочности при достаточной пластичности материала. В сталях с более низким содержанием марганца не удается достичь столь высоких показателей прочности и пластичности [9].

Изменение структурно-фазового состояния сильно отражается на механических свойствах, полученных при одноосном растяжении. По кривым деформации можно легко проследить хронологию изменения структурно-фазового состояния по способности материала к деформационному упрочнению. При наибольшей объемной доли аустенитной фазы наблюдается высокий уровень пластичности (относительное удлинение до разрушения более $30 \%$ ). Увеличение температуры отжига до 1173 К и снижение объемной доли аустенитной фазы приводит к потере пластичности, при этом показатели прочности остаются на высоком уровне, что свидетельствует о решаю- 
щей роли аустенитной фазы в деформационном упрочнении исследуемой $\mathrm{Fe}-10 \mathrm{Mn}-0.2 \mathrm{C}$ стали. Важную роль играет и исходное структурно-фазовое состояние, так как отжиг исследуемой стали при аналогичной температуре и времени выдержки после деформации при температуре 1423 К не позволяет достичь таких показателей прочности и пластичности, как после теплой прокатки. Кроме того, было показано, что отжиг деформированного при 1423 К образца при температуре 823 К не приводит к существенному изменению механических свойств исходной горячекатаной стали, в то время как прокатка при 823 K позволила увеличить предел прочности и предел текучести одновременно с увеличением пластичности материала. Таким образом, в рамках данной работы дополнительно показана эффективность предварительной деформационной обработки.

\section{ЗАКЛЮЧЕНИЕ}

В рамках проведенного исследования определено оптимальное структурно-фазовое состояние стали $\mathrm{Fe}-10 \mathrm{Mn}-0.2 \mathrm{C}$, обеспечивающее высокие показатели прочности и пластичности. Теплая прокатка позволяет получить в исследуемой стали высокий предел текучести 900 МПа и предел прочности 1627 МПа, при этом относительное удлинение до разрушения составляет $21 \%$. Предварительная деформационная обработка оказыва- ет существенное влияние на прочностные свойства исследуемой стали после термической обработки при температурах 823-923 К. Увеличение температуры отжига выше 923 К приводит к падению пластичности до показателей исходного горячекатаного состояния. Показано влияние аустенитной фазы на деформационное упрочнение исследуемой стали. При увеличении объемной доли остаточного аустенита увеличивается пластичность.

\section{СПИСОК ЛИТЕРАТУРЫ}

1. Дашкова П.В. // Металлоснабжение и сбыт. 2016. T. 3. C. 134.

2. Keeler S., Kimchi M. // World Auto Steel. 2015. V. 5. P. 275.

3. Каракозов Э.С., Сапрыгин В.Д. Холодная сварка труб. М.: Металлургия, 1978. 173 с.

4. https://www.worldautosteel.org/.

5. De Cooman B., Kim J., Chin K. High Mn TWIP steels for automotive applications. INTECH Open Access Publisher, 2011.

6. Lee S., De Cooman B.C. // Metall. Mater. Trans. A. 2013. V. 44. P. 5018.

7. Han T.-K., Park S.S., Kim K.-H. et al. // ISIJ Int. 2005. V. 45. P. 60.

8. Torganchuk V., Vysotskiy I., Malopheyev S. et al. // Mater. Sci. Engin. A. 2019. V. 746. P. 248.

9. Ящук С.В., Бакланова О.Н., Родионова И.Г. // Персп. матер. 2011. № S13. C. 968. 